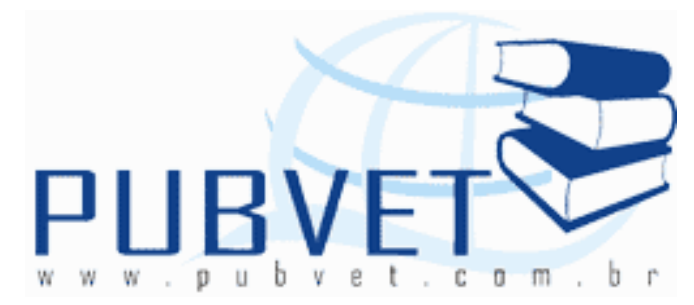

PUBVET, Publicações em Medicina Veterinária e Zootecnia.

\title{
Papilomatose canina
}

\section{Larissa Caixeta Vieira $^{1}$ e Sabrina dos Santos Costa Poggiani ${ }^{2}$}

\section{${ }^{1}$ Médica Veterinária}

${ }^{2}$ M.V., MsC., PhD. Docente do Departamento de Medicina Veterinária, União

Pioneira de Integração Social

\section{Resumo}

A papilomatose canina é caracterizada por neoformações benignas provocadas pela infecção de células epiteliais por papilomavírus espécie-específico. Seis síndromes clínicas relacionadas à papilomatose são descritas em cães, sendo estas a papilomatose oral canina, a papilomatose genital, os papilomas múltiplos de coxim plantar, os papilomas caracterizados por placas pigmentadas e os papilomas cutâneos que incluem os papilomas cutâneos invertidos. A transmissão da doença ocorre por contato direto ou indireto com secreções ou sangue provenientes dos papilomas presentes nos animais contaminados. O diagnóstico baseia-se nos achados clínicos e exames complementares. A regressão espontânea é observada na maioria dos casos, o que dificulta a avaliação da eficácia do protocolo terapêutico. Em geral, o prognóstico é bom. 
VIEIRA, L.C. e POGGIANI, S.S.C. Papilomatose canina. PUBVET, Londrina, V. 6, N. 16, Ed. 203, Art. 1357, 2012.

\title{
Canine papilomatosis
}

\begin{abstract}
Canine papillomatosis is characterized by benign neoformation caused by infection of epithelial cells by species-specific papillomavirus. Six clinical syndromes related to papillomatosis are described in dogs, which include canine oral papillomatosis, genital papillomatosis, multiple footpad papillomas, papillomas characterized by pigmented plaques and cutaneous papillomatosis which include inverted cutaneous papillomatosis. The disease transmission occurs by direct or indirect contact with secretions or blood from papillomas present in infected animals. Diagnosis is based on clinical findings and complementary tests. Spontaneous resolution usually occurs in most cases, what makes it difficult to evaluate therapeutical approach efficacy. In general, the disease prognosis is good.
\end{abstract}

\section{Introdução}

A papilomatose canina é caracterizada por neoformações benignas provocadas pela infecção de células epiteliais por papilomavírus espécieespecífico. Estes possuem oncogenes virais responsáveis pelo crescimento e divisão das células epiteliais do hospedeiro, assim como pela indução de um quadro de instabilidade genética e mutações cromossômicas ${ }^{1}$.

As lesões provocadas pelo papilomavírus podem ser cutâneas ou envolver a mucosa do epitélio escamoso da orofaringe, esôfago ou do trato genital. A expressão das funções produtivas necessárias para a replicação viral aparentemente tem sido relatada como limitada ao termino da diferenciação de células do epitélio escamoso ${ }^{2}$. Os papilomas cutâneos são pouco freqüente em cães e não há predileção sexual ${ }^{3,4,5}$.

São descritas seis síndromes clínicas relacionadas a papilomatose em cães. Entre elas, observa-se a papilomatose oral canina, a papilomatose genital, os papilomas múltiplos de coxim plantar, os papilomas caracterizados por placas pigmentadas de origem viral, também denominados verrugas 
VIEIRA, L.C. e POGGIANI, S.S.C. Papilomatose canina. PUBVET, Londrina, V. 6, N. 16, Ed. 203, Art. 1357, 2012.

planas e os papilomas cutâneos, que incluem os papilomas cutâneos invertidos. A papilomatose oral canina, considerada a forma mais comum, causa lesões em conseqüência de infecção pelo papilomavírus oral canino (COPV), e a forma cutânea de ocorrência esporádica, é desencadeada pelo papilomavírus canino tipo $1(\mathrm{CPV}-1)^{1,4,6}$.

A transmissão da doença ocorre por contato direto ou indireto com secreções ou sangue provenientes dos papilomas presentes nos animais contaminados. Alguns autores citam que a inoculação do papilomavírus oral canino através de solução de continuidade presente na epiderme ou no epitélio mucoso do animal favoreça a infecção, mas esta também pode ocorrer em decorrência de transmissão iatrogênica, utilizando-se instrumentos contaminados; fômites. A papilomatose canina é uma doença altamente contagiosa, disseminando-se em geral para todos os cães de um mesmo canil $^{1,7,8,9}$.

Geralmente, a regressão dos papilomas se deve a eventos celulares imunológicos. Nas lesões em processo de regressão são encontrados infiltrados de linfócitos $T$ que variam de acordo com o tipo de papilomavírus. Não se devem considerar somente aspectos imunológicos relacionados ao hospedeiro, mas também aspectos genéticos, nutricionais e as características próprias de cada tipo viral, que podem influenciar na forma da manifestação clínica e na evolução ou não do quadro clínico ${ }^{6}$.

A regressão dos papilomas pode variar de meses a anos. $\mathrm{Na}$ papilomatose cutânea, as lesões podem permanecer por 6 a 12 semanas antes de iniciar a regressão clínica, enquanto que o período de incubação da doença normalmente atinge 30 dias, podendo atingir períodos de 4 a 6 semanas experimentalmente ${ }^{1,7,9}$.

Os cães, após terem sido acometidos por infecções naturais ou experimentais se tornam imunes à papilomatose canina desencadeada pelo vírus. Alguns autores defendem que a imunidade humoral tem importância na prevenção da infecção, mas que esta não é efetiva na regressão das lesões. Entretanto, estes autores esclarecem que após a regressão completa das 
VIEIRA, L.C. e POGGIANI, S.S.C. Papilomatose canina. PUBVET, Londrina, V. 6, N. 16, Ed. 203, Art. 1357, 2012.

verrucosidades, o animal se torna resistente à uma reinfecção pelo mesmo tipo viral anteriormente instalado durante um período, através de uma imunidade mediada por anticorpos neutralizantes produzidos contra as proteínas, em principal L1, do capsídeo viral ${ }^{4,9,6}$.

Ocasionalmente, a regressão pode ocorrer de forma incompleta, persistindo uma pequena quantidade de papilomas. Nesses casos, podem-se observar complicações do quadro clínico ${ }^{7}$. Como forma de prevenção deve-se separar os cães com papilomatose oral canina dos animais suscetíveis e em situações de surtos da doença em canis comerciais, providenciar a vacinação autógena ${ }^{8}$.

\section{Etiopatogenia}

Os papilomavírus são um grupo de pequenos vírus DNA, não envelopados, que induzem papilomas em uma variedade de vertebrados superiores incluindo o homem. Alguns deles possuem um potencial de malignidade tanto para pessoas quanto para animais ${ }^{2}$. A grande maioria das neoplasias malignas de células escamosas de cérvix, vulva, reto e pênis em humanos estão associadas à infecção persistente por papilomavírus ${ }^{10}$.

Historicamente, os papilomavírus foram agrupados juntos com os polyomavírus formando a família Papovaviridae. No ano de 2000, o 70 Comitê Internacional de Toxonomia Viral (ICTV) reclassificou a família Papovaviridae em famílias Papillomaviridae e Polyomaviridae. A família Papillomaviridae é composta por 16 gêneros, sendo que o gênero do papilomavírus oral canino é denominado Lambdapapillomavirus ${ }^{2,6}$.

Os papilomavírus são amplamente distribuídos na natureza e foram reconhecidos inicialmente em vertebrados superiores. O vírus foi caracterizado em humanos, bovinos, coelhos, alces, eqüinos, cães, ovinos, macacos, em alguns tipos de roedores e em algumas espécies de aves. Cada tipo de papilomavírus é específico para uma espécie de hospedeiro, sendo altamente espécie - específico e razoavelmente específico para o local do desenvolvimento da lesão. Além disso, possuem tropismo por células 
VIEIRA, L.C. e POGGIANI, S.S.C. Papilomatose canina. PUBVET, Londrina, V. 6, N. 16, Ed. 203, Art. 1357, 2012.

específicas, como os queratinócitos, sendo associados exclusivamente a lesões proliferativas do epitélio escamoso ${ }^{2,8}$.

Os papilomavírus são resistentes, possuem termoestabilidade, resistência ao éter, ao $\mathrm{pH}$ ácido, ao clorofórmio, aos solventes lipídicos e às diversas condições do meio ambiente?

\section{Comportamento biológico}

Os papilomas são em sua maioria neoplasias de caráter benigno. No entanto, estão relacionados à etiologia de certos tipos de carcinomas de células escamosas na espécie canina. Lesões papilomatosas em forma de placas pigmentadas possuem potencial para transformação maligna em carcinoma de células escamosas. O desenvolvimento maligno também pode ser observado após longos períodos de latência ${ }^{1,2,3,4,7}$.

A evolução de papiloma para carcinoma em cães é uma transformação rara, tendo sido observada em um Beagle com diagnóstico de papilomatose oral e em um Collie com papilomatose oral e corneana. Acredita-se que a interação entre fatores genéticos e substâncias carcinogênicas com células infectadas por papilomavírus potencialize a capacidade de ocorrer transformação de caráter maligno. Foi observado que papilomas laríngeos humanos expostos a radiação adquirirem um potencial de transformação maligna?.

Os mecanismos moleculares induzidos pelos vírus sobre a célula transformada ainda não são bem compreendidos. Sugere-se que o vírus possa ser o responsável pelos eventos iniciais da carcinogênese, mas não pela continuidade da transformação fenotípica. Também não está claro como os fatores carcinogênicos estão envolvidos nos diferentes estágios de desenvolvimento dos papilomas e carcinomas².

O aspecto de "verruga" deve-se à proliferação e não à destruição celular. À medida que as células infectadas passam pelo processo de diferenciação e queratinização, elas se tornam permissivas à replicação viral. As partículas virais podem infectar as células adjacentes, sendo esta a razão pelo qual os 
VIEIRA, L.C. e POGGIANI, S.S.C. Papilomatose canina. PUBVET, Londrina, V. 6, N. 16, Ed. 203, Art. 1357, 2012.

papilomas cutâneos são contagiosos e aparecem agrupados. A infecção de várias células basais origina colônias celulares sobrepostas, com a aparência de "verruga", em forma de couve-flor².

\section{Sinais Clínicos}

Os papilomas orais são caracterizados como neoplasias benignas de etiologia viral que acometem animais jovens. No entanto, ressalta-se a importância destes serem diferenciados de outras neoplasias orais benignas como fibroma, lipoma, condroma, osteoma, hemangioma, hemangiopericitoma, histiocitoma, epúlides, granulomas eosinofílicos e até mesmo o tumor venéreo trasmissível que também pode ser considerado um diagnóstico diferencial quando as lesões papilomatosas se encontrarem ulceradas $^{8,11,12}$.

Normalmente, é uma doença que afeta, além da cavidade oral, o focinho, a conjuntiva e a pele. As lesões se iniciam na forma de pápulas e placas múltiplas, róseas ou brancas, pálidas, brilhantes e lisas, que progridem entre 4 a 8 semanas para lesões verrucosas semelhantes à uma couve-flor. Em geral, as lesões regridem em 3 meses, mas podem persistir por até 2 anos 1,7,11,13. 0 papilomavírus oral canino pode ser a causa de alguns papilomas localizados em pálpebra, córnea e conjuntiva ${ }^{1,7,11,13}$.

As neoplasias bucais com dimensões superiores a $1 \mathrm{~cm}$ causam dor, sialorréia, saliva sanguinolenta, debilidade extrema por anorexia prolongada. Quando associado a lesões ulceradas decorrentes de traumatismo pelos dentes, pode ser observada infecção bacteriana secundária. Da mesma forma, - quadro pode evoluir para severa disfagia e em raros casos, angústia respiratória em consequência de tumores múltiplos obstruindo as vias aéreas ${ }^{7,8,12}$.

Apesar da papilomatose oral canina possuir os sinais clínicos característicos e mais comumente observados na rotina clínica, as outras formas também podem ser reconhecidas. A papilomatose oral de modo geral é uma doença autolimitante, podendo persistir até uma regressão espontânea, 
VIEIRA, L.C. e POGGIANI, S.S.C. Papilomatose canina. PUBVET, Londrina, V. 6, N. 16, Ed. 203, Art. 1357, 2012.

embora seja necessária a remoção cirúrgica de algumas das massas se houver complicações clínicas ${ }^{7,11}$.

A papilomatose ocular é menos comum que a forma oral e acomete a córnea, conjuntiva e margens palpebrais. Trata-se de uma afeç̧ão desencadeada por partículas virais idênticas ao papilomavírus oral canino. Essa forma ocorre com mais frequência em cães de 6 meses a 4 anos de idade. No entanto, tem sido relatada em animais com mais de nove anos de idade. Alguns autores citam a ocorrência da doença em qualquer faixa etária. ${ }^{7,8} \mathrm{~A}$ papilomatose ocular tende a persistir por mais tempo que a oral e normalmente as lesões são menos numerosas ${ }^{7}$.

$\mathrm{Na}$ espécie canina, os papilomas cutâneos representam 12,5\% das neoplasias da pele. Apesar de esses tumores ocorrerem com mais frequência os cães idosos, animais jovens também podem ser acometidos. Cães das raças Cocker Spaniel, Kerry Blue Terrier, Setter Irlandês, Beagle e os cães sem raça definida são predispostos. Os papilomas múltiplos cutâneos de forma geral não estão associados à etiologia viral. O principal diagnóstico diferencial da papilomatose cutânea é a hiperplasia sebácea ${ }^{4,8}$.

As lesões cutâneas são distintas da forma oral e geralmente acometem a região da cabeça e dos membros. Caracterizam-se como tumefações lisas ou rugosas, únicas ou múltiplas, com coloração que varia de avermelhada a pigmentada, pedunculadas, alopécicas e normalmente com menos de 0,5 cm de diâmetro ${ }^{1,7}$.

O desenvolvimento de papilomas múltiplos tem sido observado no coxim plantar de cães adultos e, em geral, são massas firmes e hiperqueratóticas, situadas na região plantar de mais de um membro e freqüentemente acompanhadas por claudicação. Alguns autores acreditam que a doença seja de ocorrência esporádica. Esta enfermidade ainda não foi associada a uma etiologia viral consistente, mas foram relatados dois casos de papilomas localizado na região plantar de cães, e um deles apresentava, comprovadamente, antígeno de papilomavírus ${ }^{1,4,7}$. Na Austrália, têm-se observado papilomas cutâneos localizados na região distal dos membros, assim 
VIEIRA, L.C. e POGGIANI, S.S.C. Papilomatose canina. PUBVET, Londrina, V. 6, N. 16, Ed. 203, Art. 1357, 2012.

como nos coxins e espaços intergiditais de cães de corrida da raça Greyhound, entre 12 a 18 meses de idade ${ }^{7,8}$.

Os papilomas cutâneos de etiologia viral são de ocorrência rara e quando ocorrem, são lesões solitárias e multifocais de distribuição variável, podendo ser encontrado em qualquer região do corpo de animais infectados, tendo como agente etiológico um subtipo do papilomavírus canino, não pertencente à família Papovaviridae. Foi relatado um cão macho, de 9 meses de idade da raça Beagle diagnosticado com vários papilomas cutâneos presentes nos dígitos de todos os membros não acometendo os coxins. Acredita-se que o quadro fora causado por um papilomavírus antigenicamente e geneticamente distinto do papilomavirus cutâneo exofítico canino e do papilomavírus oral canino. No entanto, foram observadas inclusões intracitoplasmáticas que são morfologicamente idênticas aos papillomavírus conhecidos ${ }^{14}$.

A papilomatose cutânea inversa é mais comumente observada em animais jovens, entre 7 a 8 meses de idade. No entanto, pode acometer cães com até 7 anos de idade e manifesta-se como uma doença autolimitante, caracterizada como tumores múltiplos ou únicos, de 1 a $2 \mathrm{~cm}$ de diâmetro, arredondados, proeminentes, firmes e umbilicados ao centro, ou também como cornos cutâneos localizados na porção ventral do abdômen ou na região inguinal. Os papilomas invertidos cutâneos são de ocorrência rara e são causados por um único papilomavírus. O diagnóstico diferencial deve incluir os epiteliomas cornificantes intracutâneos ${ }^{1,7,8}$.

Quatro cães acometidos por papilomas invertidos, um macho e três fêmeas com idades entre cinco meses a 11 anos apresentaram regressão completa em 30 dias e nenhum sinal de recidiva das lesões após a remoção cirúrgica. Os quatro diferentes casos foram associados a um tipo diferente de papilomavírus. Em dois casos detectou-se o papilomavírus oral canino (COPV) e o papilomavírus tipo 2 (CPV2), enquanto que nos dois animais restantes, o resultado foi incerto e não foi possível precisar qual o papilomavírus envolvido 15 . 
VIEIRA, L.C. e POGGIANI, S.S.C. Papilomatose canina. PUBVET, Londrina, V. 6, N. 16, Ed. 203, Art. 1357, 2012.

A papilomatose também pode se desenvolver na forma de placas pigmentadas múltiplas que ocorrem com maior freqüência em cães mais jovens, assim como em adultos, com maior severidade observada nas raças Schnauzer miniatura e Pug. Acredita-se ser uma doença hereditária com características autossômicas dominantes que surge como lesões que progridem sem sinais de regressão, localizadas em região ventral, face medial de membro pélvico, pescoço e tronco. As placas pigmentadas múltiplas são raras e conhecidas como a forma familiar da papilomatose. O principal diagnóstico diferencial é o melanoma. Acredita-se na existência de um papilomavírus indeterminado associado a múltiplas placas virais pigmentadas em cães ${ }^{1,7,8}$.

O papiloma genital canino é a forma venérea da papilomatose e está associado provavelmente a infecções por um papilomavírus isolado recentemente. Há raros casos relatados e a descrição é incompleta. Os autores complementam que as lesões surgem na forma de placas papilomatosas proeminentes no trato genital inferior, como pênis ou mucosa vaginal ${ }^{1,8}$.

\section{Diagnóstico}

Em função da aparência macroscópica da papilomatose oral canina e dos achados de exame físico, geralmente é possível estabelecer o diagnóstico baseando-se na epidemiologia e na morfologia bem característica dos tumores. A biópsia de algumas lesões papilomatosas pode ser utilizada para confirmar o diagnóstico. Alguns tipos de papilomas, como os papilomas oculares, os cutâneos e os venéreos não são morfologicamente distintos como os papilomas orais e devem ser biopsiados e avaliados histologicamente ${ }^{7,8}$. A histologia possibilita a identificação de neoplasias intra-epiteliais, que podem estar associadas vírus oncogênicos. No entanto, não é possível através da histologia identificar o tipo de papilomavírus associado com o efeito citopático observado ${ }^{6}$.

Várias técnicas tradicionais são empregadas para a deteç̧ão de antígenos e anticorpos desencadeados pelos vírus, como por exemplo, cultivo celular, microscopia eletrônica com capacidade de localizar e demonstrar a 
VIEIRA, L.C. e POGGIANI, S.S.C. Papilomatose canina. PUBVET, Londrina, V. 6, N. 16, Ed. 203, Art. 1357, 2012.

partícula viral e a sorologia. A técnica de imunoistoquímica utilizando-se o método de complexo avidina biotina, através da coloração do antígeno viral relacionado ao grupo dos papilomavírus auxilia no diagnóstico ${ }^{6,8}$. Entretanto, este é um método de baixa especificidade e sensibilidade, e exige a presença de grande concentração de proteínas virais. Os métodos sorológicos ainda estão em estudo ${ }^{6,8}$.

A impossibilidade de cultivo dos papilomavírus em sistemas in vitro tem direcionado o desenvolvimento de técnicas de diagnóstico baseadas na identificação do DNA viral. As principais incluem a hibridização de ácido nucléico e a reação em cadeia da polimerase (PCR). O PCR tem sido amplamente utilizado para o diagnóstico e a caracterização molecular dos papilomavírus com bons níveis de sensibilidade e especificidade, e os segmentos dos genes L1 são os mais utilizados para a amplificação tanto com objetivo de diagnóstico, quanto para a caracterização molecular de novas espécies e tipos virais ${ }^{6}$.

Os diferentes métodos de hibridização foram desenvolvidos para a detecção do DNA do papilomavírus em fragmentos de tecidos e em esfregaços, incluindo a técnica de Southern blot, um método muito valioso com intuito de pesquisa, a técnica Dot blot, a hibridização in situ e a hibridização in situ com filtro, todas consideradas variações do método de hibridização. Em geral, todas essas técnicas possuem o limiar de detecção do DNA variável e esses métodos apresentam baixa sensibilidade e especificidade ${ }^{6}$.

\section{Tratamento}

O tratamento da papilomatose viral canina não é indicado em situações onde houver pequena quantidade de papilomas no animal, justamente pelo caráter autolimitante da doença e pelo fato dos animais se tornarem imunes diante de uma reinfecção. No entanto, o paciente deve ser monitorado freqüentemente pelo médico veterinário para que seja possível avaliar a evolução do quadro. A regressão espontânea é frequente na maioria dos casos, o que dificulta a avaliação da eficácia do protocolo terapêutico. Entretanto, o 
VIEIRA, L.C. e POGGIANI, S.S.C. Papilomatose canina. PUBVET, Londrina, V. 6, N. 16, Ed. 203, Art. 1357, 2012.

tratamento pode ser indicado em situações em que os tumores sejam persistentes, quando as lesões forem grandes em tamanho ou número, e possam causar a obstrução da faringe, problemas na alimentação do animal e/ou por razões estéticas ${ }^{7,8}$.

A terapia ideal é incerta em consequência da falta de conhecimento suficiente sobre os papilomavírus. Entretanto, a remoção cirúrgica das lesões, a eletrocauterização e o congelamento através da criocirurgia constituem modalidades terapêuticas que conferem cura dessas neoplasias. Além disso, o esmagamento de uma pequena quantidade de papilomas quando normalmente induz uma regressão espontânea, presumivelmente em resultado a estimulação antigênica ${ }^{4,7}$.

Acredita-se que a crioterapia, também denominada de criocirurgia ou crionecrose, tenha sido a primeira técnica pouco invasiva para o tratamento de lesões neoplásicas em cães e gatos, sendo definida como o uso controlado de baixas temperaturas, com a finalidade de destruir a lesão. Entretanto, o efeito estético a curto e médio prazo deixa a desejar quando comparado com a técnica cirúrgica tradicional e em alguns casos pode ocorrer lesões em terminações nervosas, vasos e tendões ${ }^{16}$. Tanto a excisão cirúrgica como a crioterapia tem sido efetivas contra papilomas presentes na conjuntiva e/ou na pálpebra. Em relação à excisão cirúrgica, deve-se evitar a propagação do vírus para tecidos oculares adjacentes. Tanto a crioterapia quanto a terapia a laser podem oferecer vantagens nessas situações. No entanto, a crioterapia não é recomendada em papilomas presentes na córnea ${ }^{7}$. O laser é considerado uma técnica efetiva no tratamento de lesões verrucosas resistentes e tem sido descrito em casos de papilomas respiratórios recorrentes. No entanto, mesmo a crioterapia e a ablação a laser sendo freqüentemente eficazes, ressalta-se que pode haver necessidade de repetição do procedimento e que a papilomatose oral tem sido tratada com laser de $\mathrm{CO}_{2}$ sem sucesso ${ }^{1,7}$.

Inicialmente dois tipos de vacinas foram considerados: as vacinas profiláticas que induziriam anticorpos vírus-neutralizantes prevenindo a infecção, e as vacinas terapêuticas que promoveriam a regressão das lesões já 
VIEIRA, L.C. e POGGIANI, S.S.C. Papilomatose canina. PUBVET, Londrina, V. 6, N. 16, Ed. 203, Art. 1357, 2012.

estabelecidas antes de uma possível iniciação maligna. As pesquisas de vacinas contra papilomatose são prejudicadas pela incapacidade do vírus se replicar em cultivos celulares, como também, pela dificuldade em se adaptar em cultivo de tecidos. Para produzir a vacina profilática utiliza-se a proteína L1 do capsídeo viral e para a regressão tumoral, são utilizadas as proteínas iniciais $E 1, E 2, E 6, E 7^{6}$.

Diferentes estratégias para a elaboração de vacinas têm sido utilizadas para o controle da infecção pelo papilomavírus, destacando-se entre elas, a vacina autógena, os extratos heterólogos de papilomas cutâneos que se assemelham as vacina autógenas, as vacinas de vírus purificado que foram as primeiras vacinas testadas em bovinos, as proteínas recombinantes que induzem a formação de anticorpos neutralizantes, as proteínas recombinantes que induzem a resposta imune celular e as vacina de DNA ${ }^{6}$.

As vacinas autógenas preparadas a partir de macerados de papilomas cutâneos do animal de origem têm sido recomendadas para tratamento da papilomatose canina, bovina e de coelhos. Experimentos indicam um efeito positivo na regressão das lesões, mas o seu efeito em cães é questionável, pois não foi efetiva contra papilomatoses persistentes. Acredita-se que as vacinas autógenas em cães não possuem eficácia documentada em detrimento da regressão espontânea característica da doença, o que não permite a avaliação do benefício dessa terapia. Podem ocorrer neoplasias epiteliais hiperplásicas como papiloma escamoso, tricoblastomas e carcinomas de células escamosas no local de aplicação das vacinas vivas em cães $^{1,4,6,7,8,13}$.

Uma cadela de 16 meses de idade da raça Husky Siberian com papilomatose oral canina severa, persistente e não responsiva a terapia cirúrgica a laser foi tratada com uma nova vacina recombinante contra o papilomavírus oral canino (canine oral papillomavirus vaccine) produzida no Georgetown University Medical Center. A regressão total foi observada após 15 semanas de tratamento, não houve recidiva em um período de 60 semanas após a terapia e observou-se alta circulação de anticorpos neutralizantes contra o COPV produzidos pelo animal ${ }^{1,17}$. 
VIEIRA, L.C. e POGGIANI, S.S.C. Papilomatose canina. PUBVET, Londrina, V. 6, N. 16, Ed. 203, Art. 1357, 2012.

A vacina recombinante do papilomavírus oral canino consiste na proteína principal L1 do capsídeo viral. A proteína L1 de forma isolada ou a associação das proteínas L1 e L2 expressas a partir de células bacterianas recombinantes produzem por afinidade química o capsídeo viral, mesmo sem a presença do DNA, induzem a formação de anticorpos neutralizantes como os VLPs e promovem uma resposta humoral que desenvolverá proteção contra o papilomavírus oral canino. A vacina também pode desempenhar papel na redução do desenvolvimento do carcinoma de células escamosas ${ }^{7,17}$.

Os interferons (IFNs) são moléculas de glicopeptídeos produzidos por determinadas células dos mamíferos em resposta a infecções virais bem como outros estímulos. São citocinas potentes que possuem propriedades antivirais, imunomoduladoras e antineoplásicas. Os IFNs são administrados de forma parenteral e intralesional em humanos infectados até a regressão completa das lesões, acompanhado por bons resultados em muitas situações clínicas, incluindo infecções causadas por vírus da influenza, rinovírus, herpesvírus e papilomavírus. Os mesmos autores acrescentam que doses mais baixas de IFNs administradas por via oral ao invés de doses altas fornecidas por via parenteral são comumente utilizadas em animais de companhia; o custo é bem menor, mas a eficácia é questionada. Um estudo revelou redução de células de camundongos transformadas pelo papilomavírus bovino tipo 1, utilizando-se terapia com IFN in vitro $^{7,18}$.

Antimetabólicos para inibir a síntese e proliferação de DNA viral tem sido utilizados contra o papilomavírus canino. Estes medicamentos podem ser associados a agentes quimioterápicos como a solução de 5-fluorouracil (5-FU) 0,5\%, de forma tópica, com intervalos de 24 horas durante cinco dias, seguidas de uma aplicação a cada sete dias durante quatro a seis semanas. No entanto, podem ocorrer leucopenia e trombocitopenia leves. A ingestão do produto pode resultar em uma irritação local e intoxicação sistêmica ${ }^{1,7,18}$.

A quimioterapia sistêmica e intralesional utilizando-se agentes isolados, como a vincristina, ciclosfosfamida ou doxorrubicina não foi eficaz na maioria dos tratamentos em cães ${ }^{7}$. Entretanto, um cão da raça Sharpei de um ano de 
VIEIRA, L.C. e POGGIANI, S.S.C. Papilomatose canina. PUBVET, Londrina, V. 6, N. 16, Ed. 203, Art. 1357, 2012.

idade com lesões na córnea, cavidade oral, face, no peitoral, na região inguinal e membros foi submetido a protocolo terapêutico baseado na administração intravenosa de sulfato de vincristina durante seis semanas, associado com a administração oral de levamisol a cada 48 horas, assim como espiramicina e metronidazol a cada 24 horas durante 10 dias. Os autores observaram regressão dos sintomas de forma gradual, com resultados satisfatórios ao final do tratamento ${ }^{5}$.

Alguns medicamentos modificadores de resposta biológica, como levamisol e tiabendazol, não possuem eficácia documentada em função da tendência a regressão do papilomavírus, como também em detrimento da eficácia terapêutica da cirurgia e da criocirurgiaa ${ }^{1,4}$. Outras opções incluem medicamentos imunoestimulantes como a acemanana por via subcutânea semanalmente durante 6 semanas e Propinibacterium acnes administrado 1 vez por semana até a regressão completa das lesões ${ }^{19}$. Um estudo foi realizado em 16 cães diagnosticados positivamente com papilomatose oral canina, os quais foram submetidos a administração semanal de $P$. acnes. Nesse estudo nenhum dos animais apresentou reações adversas durante e após o tratamento, e os autores concluíram que a aplicação semanal em animais jovens resultou em regressão mais rápida, quando comparada a animais mais velhos, com resolução completa na quinta aplicação ${ }^{21}$.

O etretinato é um retinóide que tem sido utilizado em alguns cães com papilomatose cutânea, seguido de resultados positivos contra placas pigmentadas caninas associadas ao papilomavírus canino. A administração de acitretina foi benéfica em um caso de papilomatose cutânea inversa em um cão 1,7 .

A utilização de terapia fotodinâmica tem induzido respostas satisfatórias em tipos severos de câncer de pele e futuramente pode desempenhar um papel importante no tratamento de papilomatoses caninas ${ }^{7}$. Em um experimento realizado com 14 cães, utilizou-se tratamento com aceturato de diminazeno. Os autores concluíram que a terapia foi eficiente, com duração reduzida em relação a outras modalidades terapêuticas, sem reações adversas. 
VIEIRA, L.C. e POGGIANI, S.S.C. Papilomatose canina. PUBVET, Londrina, V. 6, N. 16, Ed. 203, Art. 1357, 2012.

Um outro relato defende também o uso de taurolide a cada 3 dias em casos de infecção por papilomavírus oral canino ${ }^{20}$.

Há relato de êxito no tratamento da papilomatose cutânea canina com o uso de creme de imiquimode 5\%, topicamente, em intervalos de 24 a 48 horas, até regressão completa das lesões cutâneas. Deve-se evitar a ingestão do medicamento através da utilização de colar elizabetano ${ }^{1,4}$.

\section{Prognóstico}

A imunidade celular é de fundamental importância para a regressão do papiloma. Condições imunossupressoras, incluindo outras doenças e a administração de medicamentos, podem exacerbar e prolongar a infecção. Em geral, o prognóstico é bom, com regressão espontânea na maioria dos casos ${ }^{1}$.

\section{Conclusão}

Conclui-se nessa revisão de literatura que a papilomatose canina trata-se de uma enfermidade infectocontagiosa que está diretamente ligada a aspectos imunológicos do animal, assim como abrange sinais clínicos específicos relacionados a agentes etiológicos distintos. Além disso, destaca-se a necessidade de maiores estudos referentes principalmente às grandes divergências que tem sido demonstradas em relação aos agentes etiológicos e aos seus respectivos sinais clínicos. Observa-se que é uma afecção que possui abordagem terapêutica incerta justamente pelo caráter regressivo das lesões. Por fim, trata-se de uma doença contagiosa para outros cães, porém não para seres humanos.

\section{REFERÊNCIA BIBLIOGRÁFICA}

1 - MEDLEAU, L.; HNILICA K. A. Papilomatose. Dermatologia de pequenos animais - Atlas colorido e guia terapêutico. 2 ed. São Paulo: Roca, 2009 p. 141 - 142.

2 - HOWLEY, P. M.; LOWY, D. R. Papillomaviruses and their replication. In: KNIPE D. M., HOWLEY P. M. Virology. 4 ed. v. 2. Philadelphia, PA: Lippincott Willians \& Wilkins, 2001. p. $2197-2231$. 
3 - CARLTON, W. W.; MCGAVIN, M. D. Patologia veterinária especial de Thomson. 2 ed. Porto Alegre, RS: ARTMED, 1998. 535 p.

4 - RODASKI, S.; WERNER, J. Neoplasias da pele. In: DALECK, C. R.; DE NARDI. A. B.; RODASKI. S. Oncologia em cães e gatos. São Paulo: Roca, 2009. $257-258$ p.

5 - CAIRES, C. E. T.; CALDEIRA, M. I. F.; CAMPOS, C. B.; CARNEIRO, R. A. et al. Treatment of canine generalized papillomatosis with vincristine sulfate and levamisole: case report. In: 34 World Small Animal Veterinary Association Congress. São Paulo, v. 14, p. 152 - 152, 2009.

6 - FLORES, E. F. Papillomaviridae. Virologia Veterinária. Santa Maria: editora UFSM, 2007. p. $399-410$.

7 - WALL, M.; CALVERT C. A. Canine viral papillomatosis. In: GREENE, C. E. Infectious disease in the dog and cat. 3 ed. Philadelphia: W.B. Saunders, 2006. p. $73-78$.

8 - LECLERC, S. M.; CLARK, E. G. Papilomatose. In: TILEY, L. P.; SMITH JR, F. W. K. Consulta Veterinária em 5 minutos - Espécies canina e felina. 3 ed. Barueri: Manole, 2008 p. 1089.

9 - ZEE, Y. C. Papovaviridae. In: HIRSH, D. C.; ZEE, Y. C. Microbiologia Veterinária. Rio de Janeiro: Guanabara koogan, 2003. p. 320 - 322.

10 - FRAZER, I. H.; DUNN L. A. Papillomavirus. In: AHMED R., CHEN I. S. Y. Persistent viral infectious. England: John Wiley \& Sons Ltd, 1999 p. $131-140$.

11 - WILLARD, M. D. Distúrbios da cavidade oral, faringe e esôfago. In: NELSON, R. W.; COUTO C. G. Medicina interna de pequenos animais. 3 ed. Rio de Janeiro: Elsevier, 2006. p. $394-395$.

12 - FELDMAN, E. C.; ETTINGER S. J. Tratado de medicina interna veterinária - doenças no cão e no gato. 5 ed, v. 2. Rio de Janeio: Guanabara Koogan, 2008. p. $1176-1180$.

13 - FOSSUM, T. W. Cirurgia de pequenos animais. 3 ed. Rio de Janeiro: Elsevier Editora Ltda Rio, 2008. p. 361 - 366.

14 - DEBEY, B. M.; SWANSON - BAGLADI, M.; KAPIL, S. et al. Digital papillomatosis in a confined beagle. Journal of Veterinary Diagnostic Investigation. v. 13, p. $346-348$, 2001.

15 - LANGE, C. E.; TOBLER, K.; BRANDES, K. et al. Canine inverted papillomas associated with DNA of four different papillomaviruses. Veterinary Dermatology. v. 21, 2009. p. 287 - 29

16 - EURIDES, D.; DALECK, C. R.; SILVA, L. A. F.; SILVA, M. S. M. Criocirurgia. In: DALECK, C. R.; DE NARDI. A. B.; RODASKI. S. Oncologia em cães e gatos. São Paulo: Roca, 2009. $196-203$ p.

17 - KUNTSI - VAATTOVAARA, H.; VERSTRAETE, F. J. M.; NEWSOME, J. T. et al . Resolution of persistent oral papillomatosis in a dog after treatment with a recombinant canine oral papillomavirus vaccine. Veterinary and Comparative Oncology. v. 1, n.1, 2003. p. 57 - 63.

18 - PAPICH, M. G.; HEIT, M. C. e RIVIERE, J. E. Fármacos antifúngicos e antivirais. In: ADAMS, H. R. Farmacologia e terapêutica veterinária. 8 ed. Rio de Janeiro, RJ: Guanabara Koogan S. A., 2003, p. 779.

19 - TOLEDO, G. N.; SANTOS C. B. A. Eficácia do uso do Diaceturato de Diminazeno (Pirantel) no tratamento da Papilomatose canina. Nosso Clínico - Medicina veterinária para animais de companhia. v. 12, n. 67, p. $54-58,2009$.

20 - BIRICIK, H. S.; CABALAR, M.; GULBAHAR, M. Y. Oral Papillomatosis in a Dog and its Therapy with Taurolidine. Journal of the University of Veterinary and Pharmaceutical Sciences in Brno, Czech Republic. v. 77, n. 3, p. 373 - 375, 2008. 
21 - MEGID, J.; JUNIOR, J. G. D.; AGUIAR, D. N. et al. Tratamento da papilomatose canina com Propionibacterium acnes. Arquivo Brasileiro de Medicina Veterinária e Zootecnia. v. 53, n. 5, p. $574-576,2001$. 